\title{
The role of stress history on the flow of fluids through fractures
}

\author{
S. Sathar, H. J. Reeves, R. J. Cuss* and J. F. Harrington
}

British Geological Survey, Kingsley Dunham Centre, Keyworth, Nottingham NG12 5GG, UK

[Received 20 February 2012; Accepted 1 November 2012; Associate Editor: Nicholas Evans]

\section{ABSTRACT}

Understanding flow along fractures and faults is of importance to the performance assessment (PA) of a geological disposal facility (GDF) for radioactive waste. Flow can occur along pre-existing fractures in the host-rock or along fractures created during the construction of the GDF within the excavation damage zone (EDZ). The complex fracture network will have a range of orientations and will exist within a complex stress regime. Critical stress theory suggests that fractures close to localized shear failure are critically stressed and therefore most conductive to fluid flow. Analysis of fault geometry and stress conditions at Sellafield has revealed that no features were found to be, or even close to being, classified as critically stressed, despite some being conductive. In order to understand the underlying reasons why non-critically stressed fractures were conductive a series of laboratory experiments were performed. A bespoke angled shear rig (ASR) was built in order to study the relationship between fluid flow (water and gas) through a fracture surface as a function of normal load. Fluid flow reduced with an increase in normal load, as expected. During unloading considerable hysteresis was seen in flow and shear stress. Fracture flow was only partially recovered for water injection, whereas gas flow increased remarkably during unloading. The ratio of shear stress to normal stress seems to control the fluid flow properties during the unloading stage of the experiment demonstrating its significance in fracture flow. The exhumation of the Sellafield area during the Palaeogene-Neogene resulted in considerable stress relaxation and in fractures becoming non-critically stressed. The hysteresis in shear stress during uplift has resulted in faults remaining, or becoming, conductive. The field and laboratory observations illustrate that understanding the stress-history of a fractured rock mass is essential, and a mere understanding of the current stress regime is insufficient to estimate the flow characteristics of presentday fractures.

KEYwords: critical stress theory, flow, geological disposal, kaolinite, radioactive waste, Sellafield, stress history.

\section{Introduction}

SAFE management and disposal of radioactive waste in an isolated sub-surface setting is necessary to minimize the long term effects of radioactive waste on the biosphere. Deep geological disposal is currently the only available pragmatic solution for the storage and safe

*E-mail: rjcu@bgs.ac.uk

DOI: 10.1180/minmag.2012.076.8.30 disposal of radioactive waste in Europe. According to the current concepts, high level and long lived radioactive waste and spent fuel are intended to be stored/disposed of in a geological disposal facility (GDF) within a stable geological formation (host rock) at depth (typically $\sim 50-800 \mathrm{~m}$ ) beneath the ground surface. Hence, the radioactive waste is securely isolated and contained. At depth the rock mass may be a naturally fractured environment and the excavation of underground repositories is recognized to induce additional fractures (Bossart et al., 
2002; Rutqvist et al., 2009). The zone of the host rock in the vicinity of the underground opening whose hydromechanical properties are modified as a consequence of excavation activities are referred to as excavation damaged zones (EDZ) (Tsang et al., 2005). Depending on the in situ stress conditions, preferential pathways may form along faults, joints and the EDZ.

Fluids, such as gases and water, are expected to play a role in the transport of radionuclides away from the GDF. The conductivity of fluids through a fault or fracture is understood to be controlled by the interplay of fracture orientation and principal stress directions (Barton et al., 1995; Finkbeiner et al., 1997). Around the GDF there are two distinct zones with differing fracture orientations, fracture densities and fluid flow properties: (1) the EDZ where an intricate range of fracture orientations are present in a complex localized-stress field; and (2) the far field zone where pre-fractured host rock may be present.

It has been proposed that fractures and faults that are oriented parallel to the maximum horizontal stress orientation $\left(\sigma_{\operatorname{Hmax}}\right)$ experience the lowest normal stresses acting across them and therefore will undergo the least amount of closure and will thus be the most permeable (Heffer and Lean, 1993). This is based on the assumption that the fractures and faults experiencing the least amount of stresses will offer minimum resistance to flow and therefore will have relatively high permeability. However, observations by Laubach et al. (2004) on a number of basins in western United States using core permeability, stress measurements and fluid flow datasets have shown that at a depth of $>3 \mathrm{~km}$, the open fractures are not aligned parallel to the $\sigma_{H \max }$ direction as previously understood. Hence, in situ stress orientations cannot be realistically used as an indicator for predicting fluid flow in fractured rocks.

Barton et al. (1995) proposed that fractures whose state of stress are close to the failure criterion are more likely to be conductive because of the localized failure as a consequence of the large shear component acting along the fracture surfaces. Such fractures are termed 'critically stressed' and are oriented approximately $30^{\circ}$ to the $\sigma_{\text {Hmax }}$ direction (Rogers and Evans, 2002; Rogers, 2003). In order to apply the critical stress theory to fracture flow, the in situ stress field acting along all faults and fractures in a volume of rock can be resolved into shear and normal stress components. When the magnitude and direction of the stress field has been constrained, the shear stress $(\tau)$ and normal stress $\left(\sigma_{n}\right)$ acting on a fracture surface can be expressed by (Jaeger et al., 2007):

$$
\begin{aligned}
\tau & =\beta_{11} \beta_{21} \sigma_{1}+\beta_{12} \beta_{22} \sigma_{2}+\beta_{13} \beta_{23} \sigma_{3} \\
\text { and } \sigma & =\beta_{11}^{2} \sigma_{1}+\beta_{12}^{2} \sigma_{2}+\beta_{13}^{2} \sigma_{3}
\end{aligned}
$$

where, $\beta_{\mathrm{ij}}$ are the direction cosines between the fracture surface and the stress tensor and $\sigma_{1}, \sigma_{2}$, and $\sigma_{2}$ are the magnitude of the maximum, intermediate, and minimum principal stresses, respectively.

When the shear stress and normal stress on the faults and fracture surfaces are plotted with respect to the in situ stress field in a Mohr space, the faults and fractures that are scattered above the MohrCoulomb failure criterion are termed critically stressed and hence expected to be conductive (Fig. 1). Critically stressed fractures are expected to be present amongst the numerous complex fracture networks within and around the EDZ and in the far field around the GDF.

In the present integrated field and experimental study, the relationship between fracture and stress tensor orientations with respect to the flow of fluids through fractures in Sellafield area, UK, has been investigated. A reappraisal of the complete dataset has been undertaken (Reeves, 2002; Reeves et al., 2003) in order to apply the critical stress approach to the Sellafield area of the UK. The distributions of conductive and non-conductive fractures with respect to in situ stress conditions are examined to comprehend the relationship between in situ stress and fracture flow. Furthermore, the effect of loading and unloading on the flow of fluids (water and gas) through an idealized experimental fracture surface and its implications for fluid flow have also been investigated.

\section{Field studies}

\section{Location and methods}

The Sellafield area, in west Cumbria lies in a transitional structural zone between the western margin of the Lower Palaeozoic Caledonian basement (Lake District massif) and rocks of the younger East Irish Sea Basin (Michie, 1996). The lower Palaeozoic basement rocks consist of a thick pile of extrusive, volcanic and volcaniclastic rocks known as the Borrowdale Volcanic Group (BVG). Sandstones, mudstones, and breccias of Permo-Triassic age make up the rocks of the East Irish Sea Basin.

As a part of the UK Nuclear Industry Radioactive Waste Executive's (Nirex) Sellafield 

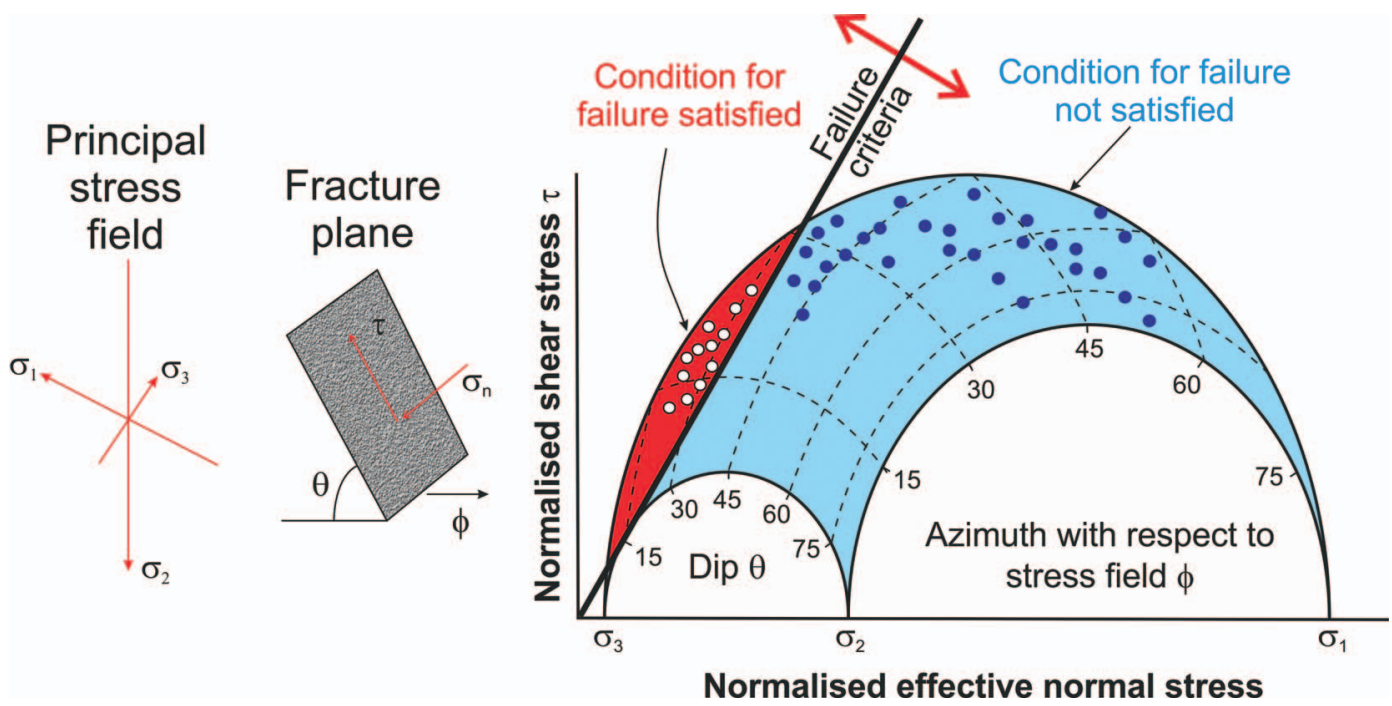

Fig. 1. Critical stress hypothesis (adapted from Barton et al., 1995; Jaeger et al., 2007; Rogers, 2003). The threedimensional Mohr diagram represents the shear stress and normal stress acting along a fracture in response to the in situ stress field. The open circles represent fractures experiencing state of stress above the failure criterion and therefore subject to shear failure. The closed circles represent fractures for which the stress state is insufficient to induce shear failure.

investigations, 29 deep boreholes were drilled totalling about 27,500 meters in overall length (Bowden et al., 1998). Systematic geological logging of the cores was performed followed by mineralogical, geochemical and geotechnical studies. In situ stress analysis was carried out to understand the present day stress conditions of the rocks (Nirex, 1996). In situ hydraulic testing was also performed to assess the hydraulic properties of the rock mass to identify the flow zones (Armitage, 1996).

The BVG was planned as a possible host rock for the future radioactive waste repository in the Sellafield area. The BVG consists of Ordovician (Caradocian) pyroclastic volcanic rocks which originated from a subaerial, subduction related, calc-alkaline volcanic field that resulted from the closure of the Iapetus ocean (Millward et al., 1994). The matrix permeability of fluids through the BVG is very low. However, fluid flow through BVG has been determined to occur via complex networks of discontinuities such as faults and joints existing within them (Nirex, 1997).

The dataset presented here was acquired by Nirex as a part of their preliminary investigations into the Sellafield area to assess its suitability as a potential site for deep underground disposal of intermediate-level and long-lived low-level radio- active waste. Fracture orientation datasets, in situ stress measurement datasets, and fluid flow indicators (from hydrogeological production tests, short interval tests and mineralogical and/ or petrographic examination of discontinuities within the borehole core) were collected during the drilling and geophysical logging of the 29 deep boreholes scattered around the Sellafield area (Armitage et al., 1996; Bowden et al., 1998; Nirex, 1996; Nirex, 1997).

Ultrasonic geophysical logging tools such as borehole televiewers (BHTV/UBI) were used to gather a high resolution detailed $360^{\circ}$ record of the borehole elongation and distribution of natural fractures. Features such as breakouts were easily discerned by the prominent distortion to the waveforms in the BHTV image $\log$ as a consequence of an increase in the number of fractures encountered around the breakout (Rider, 1986; Paillet and Kim, 1987). From the sine wave fitting routines of the acoustic image from the BHTV/UBI tool, the azimuth and dip of the fractures were deduced (Reeves et al., 2002). The presence of mineralized zones in the fractures were inferred by a comparison between the amplitude of the reflected signal (AMWF) and the two way travel time (TTWF) images; with open fractures showing up in both images and 
mineralized fractures evident only in the AMWF image. The conductive and resistive features were identified in the borehole by means of electrical imaging tools namely, the Formation MicroScanner (FMS) and the Fullbore Formation MicroImager (FMI) (Standen, 1991). The FMS and FMI measure the ease with which electrical current can be conducted by the borehole walls and aid in inferring zones of high conductivities which are marked by the presence of pore fluids within fractures or flow paths. The FMS/FMI logs display sharp electrical contrasts in the borehole images depending on the presence of conductive fluids, cemented horizons, and also helps to decipher geometrical relationship such as high dip in a sequence with low structural dip (Rider, 1986).

Regional stress maps for the Sellafield area were produced by Brereton et al. (1997) from the information gained from the breakouts observed within the BVG and the Permo-Triassic rocks within the locality. From the analysis of elongation of the borehole cross-section, in situ stress orientation data was acquired.

\section{Field observations and results:}

Figure 2 shows the UK regional stress regime (Evans and Brereton, 1990) displaying the distinctive NW-SE $\left(135 / 315^{\circ}\right) \sigma_{\text {Hmax }}$ in the UK and exhibits the location and alignment of the $\sigma_{\text {Hmax }}$ oriented breakout results derived from the in situ stress investigations of the top hundred metres of the BVG in the Sellafield area in addition to its relationship to the existing geological structures. The data demonstrates a mean orientation of $159 / 339^{\circ}$ for the $\sigma_{H \max }$ orientation with values ranging from $118 / 298^{\circ}$ to $190 / 010^{\circ}$ and came from the reappraisal of the stress tensor orientations undertaken by Reeves (2002).

A frequency plot of the orientations of fractures observed within the flowing and non-flowing area identified from the short interval test (SIT) investigation from Sellafield Borehole RCF3 (Armitage et al., 1996) shows that the flowing fractures are not oriented parallel to the $\sigma_{\mathrm{Hmax}}$ direction (Fig. 3). On the contrary, non-flowing fractures were observed to be aligned parallel to $\sigma_{\text {Hmax }}$ direction. From the critical stress analysis of the flow zones and the short interval test zones in Sellafield Borehole RCF3, no critically stressed fractures which are in equilibrium with the in situ stress regime, could be established (Fig. 4). All the flowing and non-flowing fracture data points plot below the Mohr-Coulomb failure envelope for a coefficient of friction of 0.6. Moreover, the flowing and non-flowing fracture datasets are dispersed across the Mohr diagrams with the flowing fractures forming a subset in the upper zone of the Mohr space whereas the non-flowing fractures are randomly scatter around the lower zones within the Mohr space. These observation would suggest that the critical state approach is not applicable to this example in the Sellafield area, which is also concluded from the in depth study presented in Reeves (2002).

\section{Experimental studies}

\section{Methodology}

All of the experiments reported in the present study were performed using the bespoke angled shear rig (ASR) (Fig. 5) built at the Transport Properties Research Laboratory (TPRL) of the British Geological Survey. The ASR consists of two stainless steel blocks with a $60 \mathrm{~mm} \times 60 \mathrm{~mm}$ $\times 50 \mu \mathrm{m}$ clay gouge sample sandwiched between them. Saturated kaolinite clay paste (gravimetric water content of $80 \%$ ) was used as the sample material in this study. Unlike standard direct shear experiments, the top and bottom blocks can be oriented at different angles to the normal load/ horizontal displacement. Experiments have been conducted on horizontal blocks and at angles of 15,30 and $45^{\circ}$. However, the current data are all for a fracture oriented at $30^{\circ}$ to the direction of horizontal movement (or $60^{\circ}$ to the normal stress direction). Normal load was applied using a servo controlled Teledyne ISCO-260D syringe pump pressurizing an Enerpac single acting hydraulic ram connected to a rigid loading frame. Pore fluid (water or helium) was introduced through the centre of the top block by means of a Teledyne ISCO 500D syringe pump connected in series to a gas-water interface vessel. Pore pressure transducers, attached to ports which are positioned orthogonally to each other at $15 \mathrm{~mm}$ from the central pore fluid inlet allowed measurement of pore pressures within the fracture surface (Fig. 5a).

The complete experimental programme conducted in excess of 40 separate experiments. The results from four experiments are presented and summarized in Table 1. These experiments were conducted at constant injection pressure with cyclic normal load steps from 0.3 to 3 to $0.3 \mathrm{MPa}$ in a total of approximately 25 steps. 


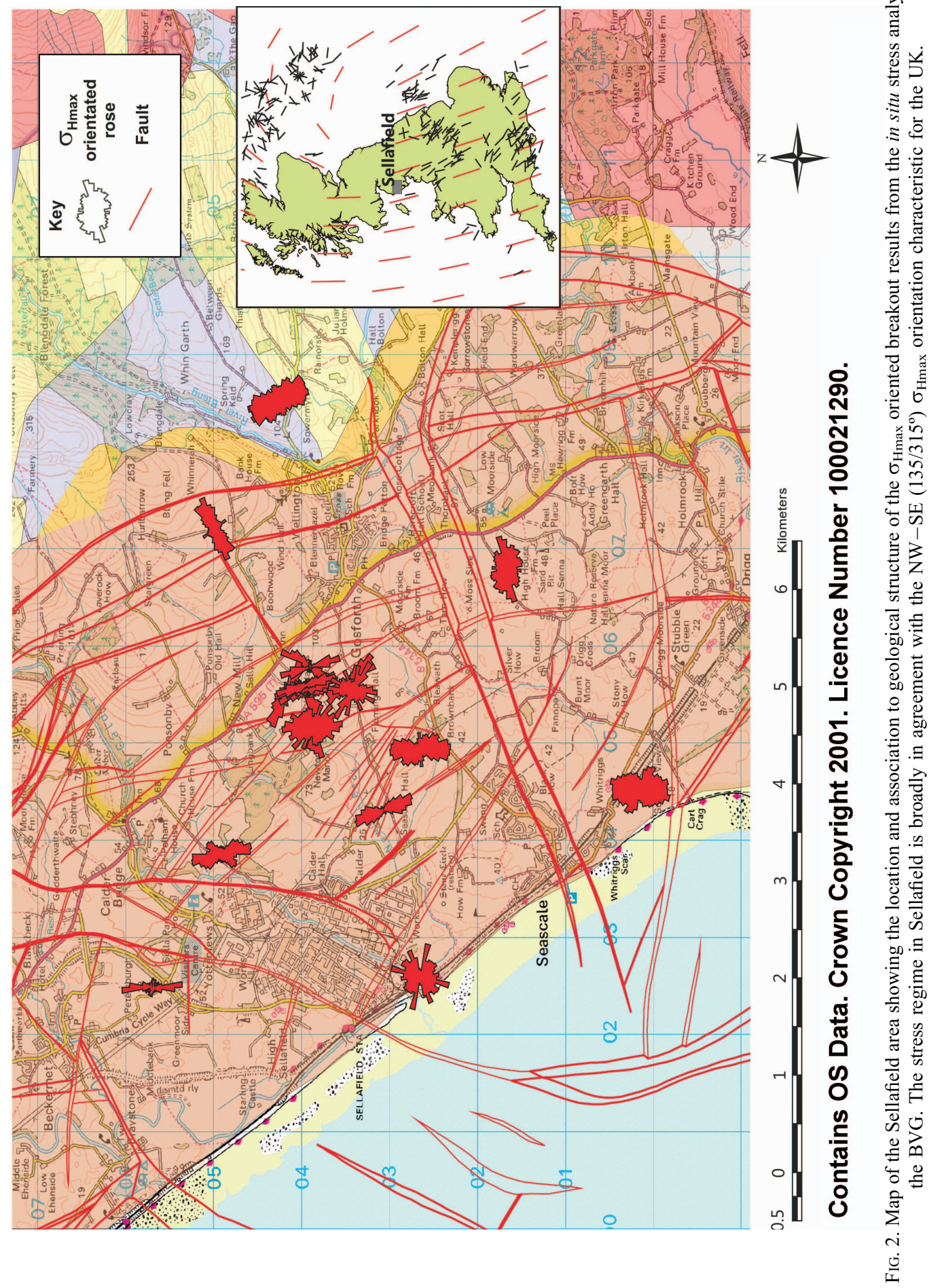




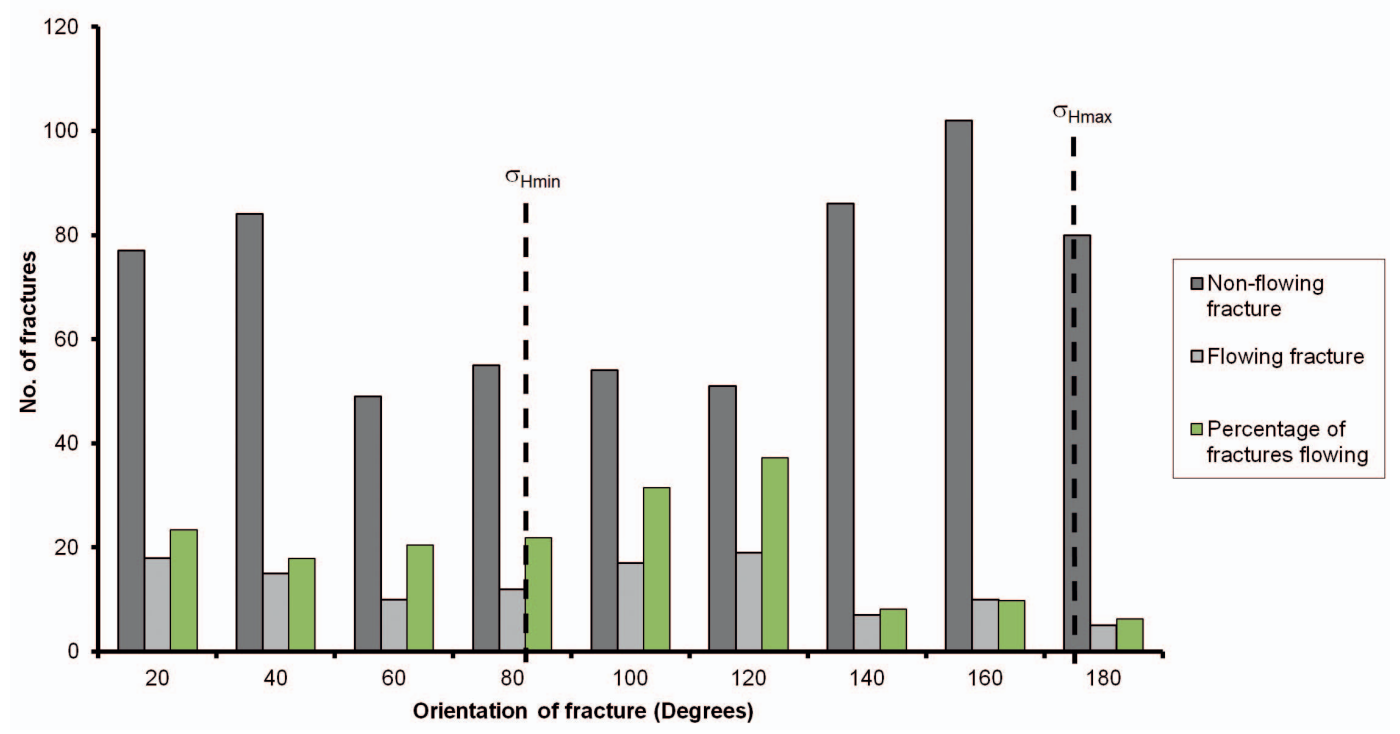

FIG. 3. Plot showing the orientation of the fractures observed within the flowing and non-flowing areas in a borehole from the Sellafield area. Few flowing fractures with preferred orientation parallel to $\sigma_{\text {Hmax }}$ direction were detected. Example taken from the reappraisal of the relationship between fracture and stress tensor orientations with respect to the flow of fluids through fractures at Sellafield, undertaken by Reeves (2002).

Repeat results are presented for two water injection and two gas injection tests. Note that although the ASR is capable of performing tests during active shear, the presented results were conducted without shear. However, the slope of the experimental fracture plane resulted in an unavoidable shear movement of $\sim 5 \pm 2 \mu \mathrm{m}$ during loading from 0 to $3 \mathrm{MPa}$. The evolution of shear load with loading was measured using a load cell fitted laterally to the top-block (Fig. 5).

A pore water pressure of $1 \mathrm{MPa}$ was used during water injection tests, which was of sufficient magnitude to initiate flow. A higher gas injection pressure of $3.55 \mathrm{MPa}$ for ASR_Tau07 and $4.95 \mathrm{MPa}$ for ASR_Tau08 was necessary in order to initiate flow. Normal load on the fracture surface was varied approximately every $24 \mathrm{~h}$ to give optimum time for attaining stress and pore-water pressure equilibrium within the fracture surface. Data were logged every 2 minutes using LabVIEW. The data were processed based on the formulations detailed in Gutierrez et al. (2000) and Cuss et al. (2011).
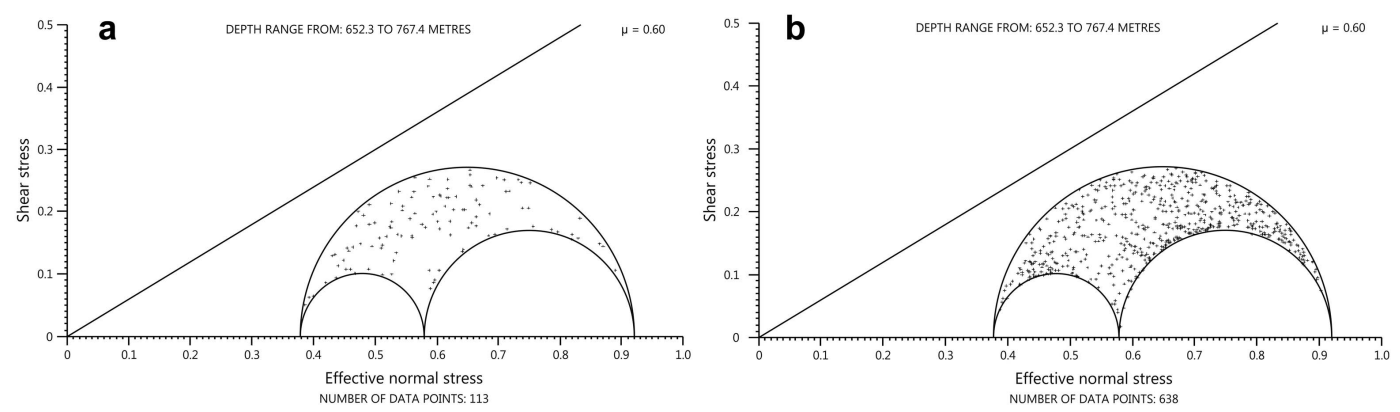

FIG. 4. Mohr diagrams showing the distribution of (a) flowing and (b) non-flowing fractures in the Sellafield area, UK. None of the fractures are critically stressed at the present-day conditions. 

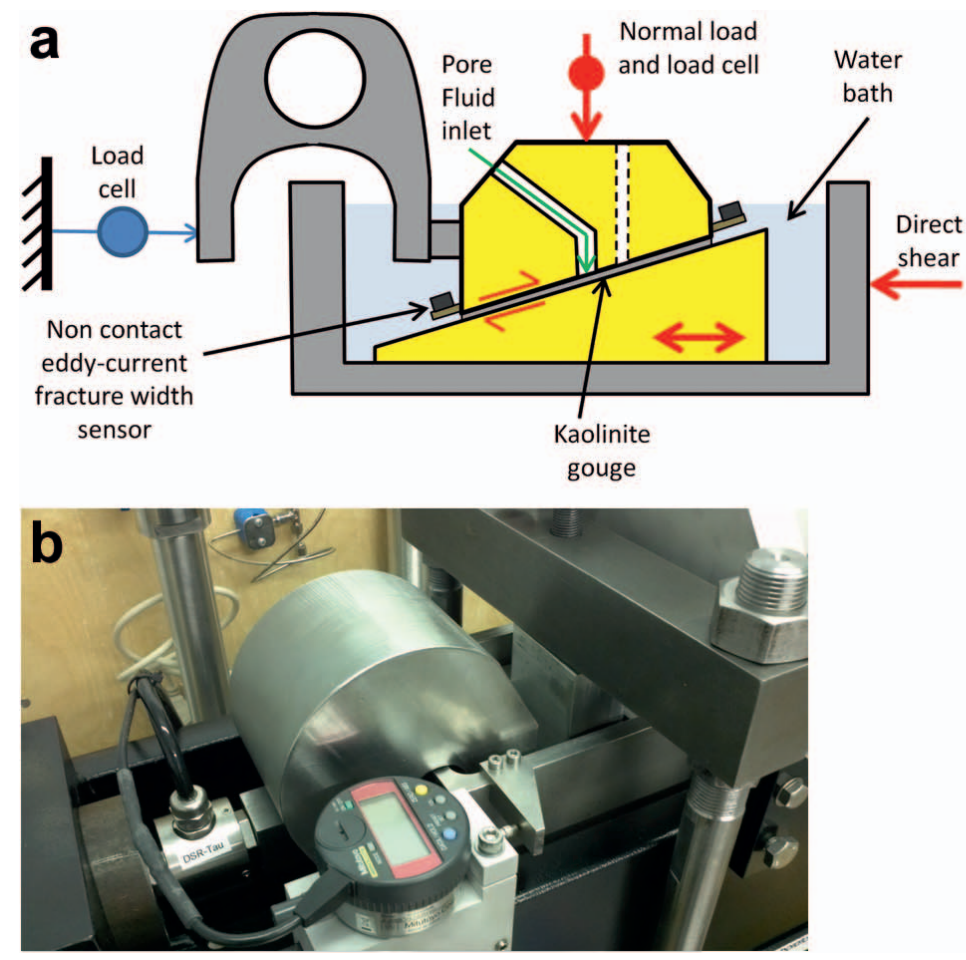

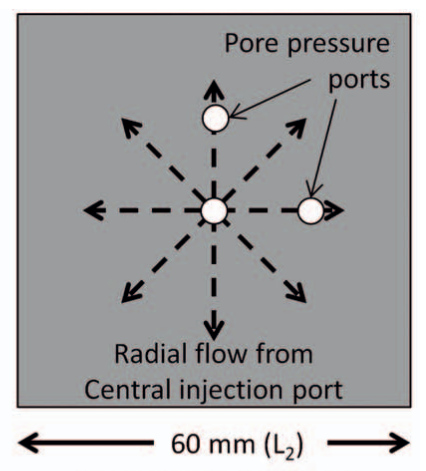

Plan view of slip-plane

FIG. 5. The angled shear rig (ASR). (a) Schematic showing the main components of the apparatus. (b) The ASR. The clay gouge sits in between the top and bottom blocks and the pore fluid is injected through an inlet located at the centre of the top block.

\section{Experimental observations and results}

The results of water and helium injection experiments during a loading and unloading cycle are presented in Figs 6 and 7, respectively.

As seen in Fig. 6, water flow rate decreased during loading by approximately an order of magnitude, but only partially recovered during unloading (hysteresis). In test ASR_Tau01 flow rate decreased from 86 to $6 \mu \mathrm{h} \mathrm{h}^{-1}$ during loading from 0.2 to $3 \mathrm{MPa}$. During unloading from 3 to
$0.1 \mathrm{MPa}$ flow rate recovered from 6 to $23 \mu 1 \mathrm{~h}^{-1}$ (Fig. 6b,c). The shear stress to normal stress ratio decreased from a starting value of 1.3 to 0.7 during loading, whereas during the unloading the shear stress to normal stress ratio increased steadily with each unit step in the unloading cycle to a final value of 2.3 at $0.19 \mathrm{MPa}$ (Fig. 6d). Similar to ASR Tau01, in test ASR Tau05 flow rate decreased from 48 to $5 \mu \mathrm{h}^{-1}$ during loading from 0.2 to $3 \mathrm{MPa}$ and the flow rate recovered to

TABLE 1. List of fluid injection experiments carried out as a part of the present study.

\begin{tabular}{llcc}
\hline Type of experiment & Experiment code & Injection pressure (MPa) & Duration (days) \\
\hline \multirow{3}{*}{ Water injection } & ASR_Tau01_30wLU & 1.00 & 14 \\
\multirow{3}{*}{ Gas injection } & ASR_Tau05_30wLU & 1.00 & 27 \\
& ASR_Tau07_30gLU & 3.55 & 30 \\
& ASR_Tau08_30gLU & 4.95 & 36 \\
\hline
\end{tabular}



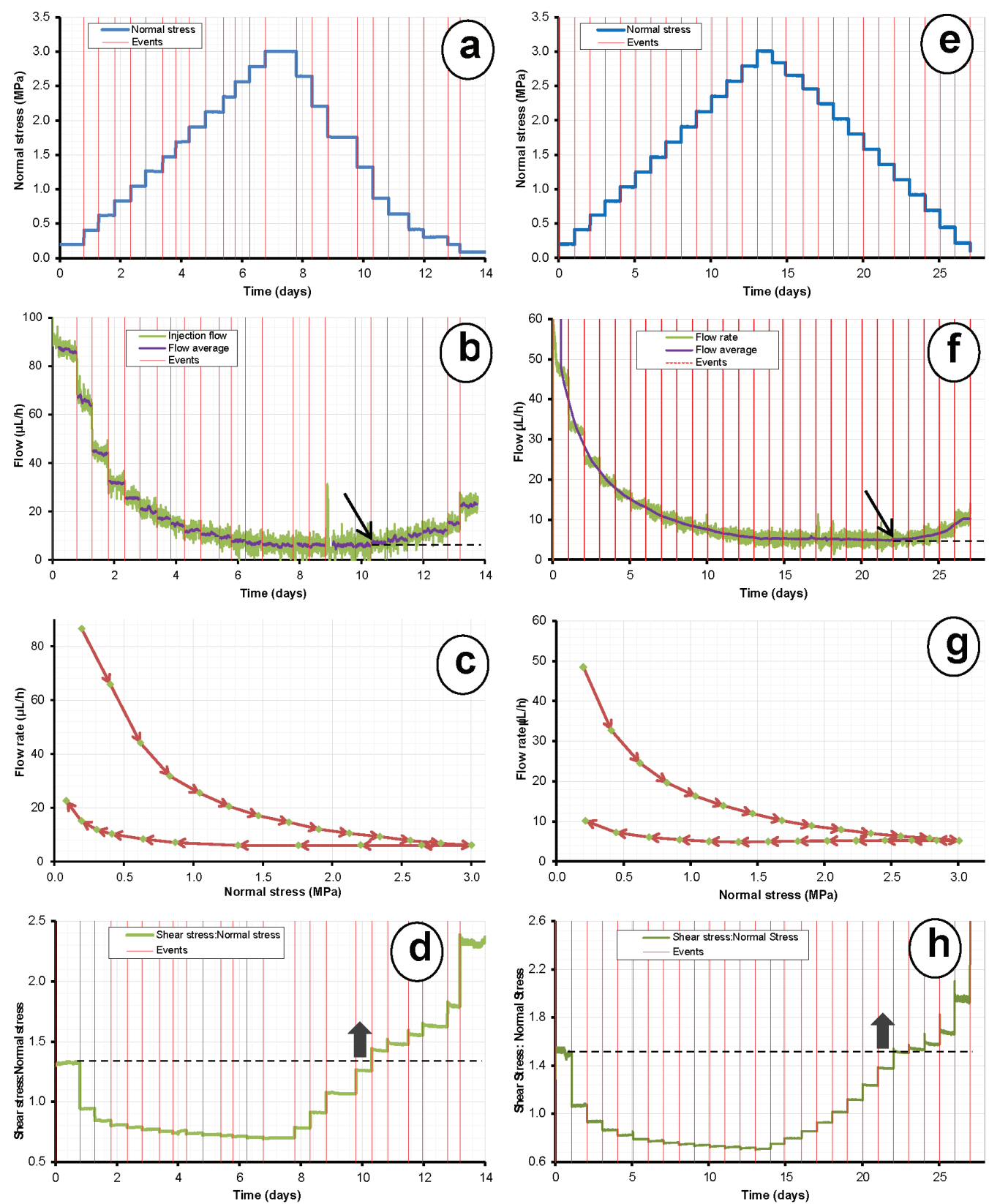

FIG. 6. Graphs showing the mechanical and flow properties of an idealized experimental fracture surface during water injection experiments $(a-d)$ ASR_Tau01_30wLU and $(e-h)$ ASR_Tau05_30wLU. $(a)$ and $(e)$ Graph displaying the loading and unloading stages. $(b)$ and $(f)$ Flow rate $v s$. time plot showing the variation in flow rate with loading and unloading. The arrows correspond to an increase in flow rate when the shear stresses to normal stress ratios are higher than the starting values [see $(d)$ and $(h)$ ]. $(c)$ and $(g)$ Flow rate $v s$. normal stress plot showing the partial recovery of flow rate during unloading. It should be noted that only a quarter of the initial flow rate was recovered during unloading. $(d)$ and $(h)$ Variations in shear stress to normal stress ratio during loading and unloading. The arrows indicate shear stress to normal stress ratios during unloading which are greater than the initial values and signifies an enhancement in flow rate [see $(b)$ and $(f)]$. 
$10 \mu \mathrm{h} \mathrm{h}^{-1}$ during unloading to $0.1 \mathrm{MPa}$ (Fig. $6 f, g$ ). Shear stress to normal stress ratio decreased from 1.5 to 0.7 during loading and during unloading the ratio increased steadily with each step to finally achieve 2 at $0.22 \mathrm{MPa}$ (Fig. 6h). Even though the initial flow rates in ASR Tau01 and ASR Tau05 were remarkably different (86 and $48 \mu 1 \overline{\mathrm{h}}^{-1}$, respectively) prior to loading, the flow rate at maximum loading is similar for both tests, with values of 6 and $5 \mu 1 \mathrm{~h}^{-1}$, respectively (Fig. 6c,g). Furthermore, the shear stress to normal stress ratio evolved in a similar way in response to normal load variations in both tests (Fig. $6 d, h$ ).

As seen in Fig. 7, helium flow rate evolution during cyclic loading was remarkably different to that observed during water injection. In ASR_Tau07, gas flow rate increased and decreased arbitrarily during loading from 0.25 to $1.5 \mathrm{MPa}$. However, during further loading from 1.5 to $3 \mathrm{MPa}$ a reduction in flow rate with increasing load was observed; flow rate decreased from 200 to $90 \mu \mathrm{h} \mathrm{h}^{-1}$ (Fig. $7 b, c$ ). In contrast to unloading during water injection, gas flow rate increased by an order of magnitude from $90 \mu \mathrm{h}^{-1}$ to in excess of $1000 \mu \mathrm{h} \mathrm{h}^{-1}$ during unloading from 3 to $0.25 \mathrm{MPa}$ (Fig. 7c). The flow rate was observed to rise when the shear stress to normal stress ratio was greater than unity during the unloading cycle (Fig. 7d). Similar complexity in flow rate evolution during loading and unloading was observed in test ASR_Tau08. The gas flow rate increased and decreased during loading between 0.4 and 1.2 $\mathrm{MPa}$. Loading stages from 1.2 to $3 \mathrm{MPa}$ resulted in a steady decrease in flow rate from 550 to $276 \mu 1 \mathrm{~h}^{-1}$ (Fig. $7 f, g$ ). The shear stress to normal stress ratio during loading and unloading was similar to that observed in ASR Tau07 (Fig. $7 d, h$ ). Significant gas flow rate increase occurred when the shear stress to normal stress ratio increased above unity during unloading.

A comparison of the results from the water and gas injection experiments reveals that flow rate generally decreased during loading and increased during unloading. Hysteresis in flow was observed during a loading-unloading cycle in both the water and gas injection experiments. The responses of water and gas flow were remarkably different during the unloading stages. Shear stress versus normal stress plots for both water and gas injection experiments showed similar behaviour with a prominent hysteresis in shear stress during the unloading stage (Fig. 8).

\section{Discussion}

It has been reported in the literature (Heffer and Lean, 1993) that fractures and faults oriented parallel to $\sigma_{\text {Hmax }}$ direction are likely to be most conductive. However, field observations from the Sellafield area suggest that there is no apparent relationship between the fracture orientation and the $\sigma_{\text {Hmax }}$ direction. Additionally, open and flowing fractures were not observed to be oriented parallel to $\sigma_{\text {Hmax }}$ direction (Fig. 3). The present observation is in agreement with the misalignment of $\sigma_{\text {Hmax }}$ and open fractures in the East Texas Basin, Val Verde Basin, Green River Basin and Powder River Basin reported by Laubach et al. (2004). Interestingly, in the present study, nonflowing fractures were observed to be oriented relatively parallel to $\sigma_{\text {Hmax }}$ direction affirming that $\sigma_{\text {Hmax }}$ direction on its own accord cannot be used as a predictive method for fluid flow directions as proposed previously. Furthermore, critical stress analyses of the rocks in the Sellafield area revealed that no fractures were critically stressed and are in frictional equilibrium with the in situ stress field.

One possible explanation for the non-applicability of critical stress analysis to the Sellafield area is the complex tectonic history. Lewis et al. (1992) have proposed a rapid PalaeogeneNeogene uplift and inversion, with uplift of approximately $2 \mathrm{~km}$ (Chadwick et al., 1994). This has resulted in stress relief along fractures and faults to the present stress state which is below critical stress conditions.

The experimental results confirm a strong relationship between normal stress and flow, as expected. Water and gas flows were significantly decreased due to increasing normal stress. The decrease in flow is mainly due to the constriction of fluid pathways due to a decrease in fracture width during normal loading. Similar decrease in fault flow with increased effective normal stress has been reported by Brace et al. (1968), Huenges and Will (1989), Pratt et al. (1977) and Rice (1992). The arbitrary response of gas flow during the initial loading stages might have been due to the formation or enlargement of gas pathways as a result of the movement of the fracture blocks under low normal stress during initial loading. However, gas flow was significantly enhanced during unloading which suggests that water and gas flow responds in a significantly different way. The desiccation of the fault gouge by the gas resulting in enhanced flow rates cannot be entirely 

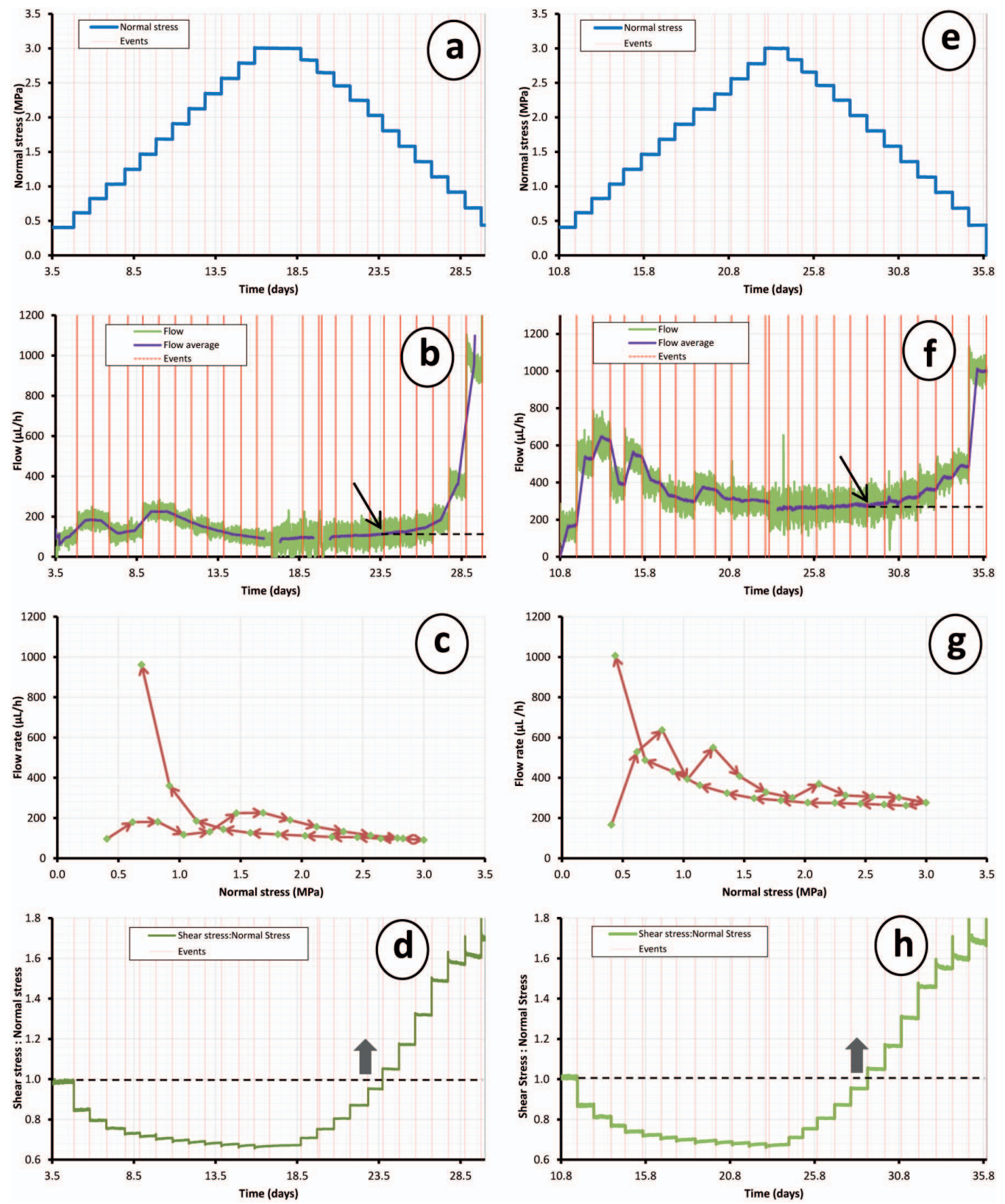

FIG. 7. Graphs showing the mechanical and flow properties of an idealized experimental fracture surface during gas injection experiments $(a-d)$ ASR_Tau07_30gLU and $(e-h)$ ASR_Tau08_30gLU. $(a)$ and $(e)$ Graphs displaying the loading and unloading steps. $(b)$ and $(f)$ Flow rate variation during loading and unloading stages. Flow rate during unloading is significantly higher than the initial flow rate. The arrows correspond to an increase in flow rate when the shear stresses to normal stress ratios are higher than the starting values [see $(d)$ and $(h)$ ]. Also note the remarkable differences in flow rate evolution between the water injection (Fig. 6) and the gas injection experiments. (c) and $(g)$ Flow rate $v s$. normal stress plot showing the substantial increase in flow rate during unloading stages. $(d)$ and (h) Shear stress to normal stress ratio variations with loading and unloading. The arrows indicate shear stress to normal stress ratios during unloading which are greater than the initial values and indicates an enhancement in flow rate $[$ see $(b)$ and $(f)]$. 


\section{STRESS HISTORY AND FLUID FLOW}

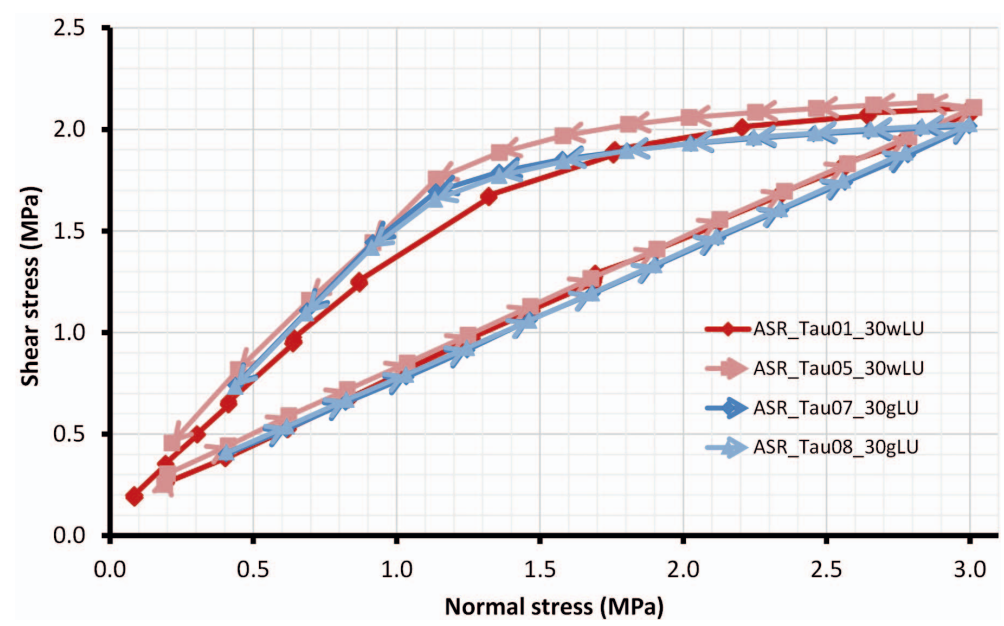

FIG. 8. Shear stress vs. normal stress plot showing prominent hysteresis during the unloading stages of both water and gas injection experiments. The graphs show remarkable similarity in the way shear stress fluctuates with normal stress variations.

ruled out. However, the rapid response of flow rate to variations in normal stress during unloading suggests that desiccation would not have played a major role in significantly affecting the flow rate.

Zoback et al. (1985) and Brudy et al. (1997) have shown that the ratio of shear stress to normal stress is crucial in controlling permeability and in the movement of gas through fractures. The close relationship between fracture flow and the shear stress to normal stress ratio during the unloading stages in the present experiments also points towards its significance in understanding the flow of fluid through fractures in the BVG within the Sellafield area that have undergone stress relaxation via uplift and inversion since the end of Cretaceous. Moreover, experimental results have shown remarkable hysteresis in the shear stress versus normal stress plots (Figs 6 and 7). The hysteresis in shear stress during unloading may be attributed to the cohesive strength of the kaolinite clay gouge. In the case of a fractured rock formation undergoing considerable uplift, such as the BVG in the Sellafield area, stress relaxation is likely to result in high shear stress to normal stress ratio. Fluid flow under high shear stress to normal stress ratio as observed in the experimental fracture study becomes very probable and may explain the occurrence of flowing fractures in the Sellafield area. This highlights that an understanding of the stress history of the fracture or fault surface is essential to effectively predict the present fluid flow properties of those features. A mere knowledge of the present day in situ stress is insufficient to describe the flow properties of subsurface fluids through fractured rocks. The prevalence of flowing fractures in the Sellafield area irrespective of the current stress state not achieving critical values implies that the once critically stressed rocks have undergone stress relaxation during the Palaeogene-Neogene uplift.

\section{Summary and conclusions}

The fluid flow properties of fractures within the BVG in the Sellafield area have been investigated in the present study. The results show that the stress state is below the critical stress criterion and indicates that the rocks have undergone stress relaxation as a result of exhumation associated with the complex geological history of the area. Experimental fracture flow studies performed to understand the occurrence of flowing fractures have shown that:

(1) Fluid flow through fractures decreases with increase in normal stress, as expected.

(2) The effect of stress relaxation on water and gas flow through a fracture surface is remarkably different. During water flow experiments considerable hysteresis is seen with only a partial recovery of the initial flow rate. Hysteresis is also seen in gas flow experiments. However, flow became much greater than the initial flow.

(3) Understanding the shear stress to normal stress ratio is vital in predicting the flow 
properties of fractures and faults. Features experiencing high shear stress to normal stress ratios are expected to be more conductive. Moreover, high shear stress to normal stress scenarios are likely to be more prevalent in regions experiencing stress relaxation due to structural uplift or removal of the overburden as in the case of the Sellafield area.

(4) Substantial hysteresis in shear stress during unloading (stress relaxation) indicates that fracture flow is significantly altered by the stress history.

There is considerable field evidence of the applicability of the critical stress theory to numerous basins worldwide. It had been anticipated that this approach would aid the understanding of the hydrogeology of the Sellafield area and it was unexpected that the theory was not supported by the field data. It can therefore be concluded that uplift and a complex stress history has a profound impact on the critical stress theory and the flow properties of faults. The stress history has to be included in an analysis and this hypothesis is supported by the experimental observations where considerable hysteresis is observed in flow and stress during unloading.

\section{Acknowledgements}

A part of the research presented here was funded by the European Atomic Energy Community's Seventh Framework Programme (FP7/2007-2011) FORGE project under Grant Agreement No. 230357. This paper is published with the permission of the Executive Director, British Geological Survey (NERC).

\section{References}

Armitage, P., Holton, D., Jefferies, N.L., Myatt, B.J. and Wilcock, P.M. (1996) Groundwater Flow Through Fractured Rock at Sellafield. Nuclear Science and Technology EUR 16870. European Comission, Brussels.

Barton, C.A., Zoback, M.D. and Moos, D. (1995) Fluid flow along potentially active faults in crystalline rock. Geology, 23, 683-686.

Bossart, P., Meier, P.M., Moeri, A., Trick, T. and Mayor, J.-C. (2002) Geological and hydraulic characterisation of the excavation disturbed zone in the Opalinus Clay of the Mont Terri Rock Laboratory. Engineering Geology, 66, 19-38.

Bowden, R.A., Bumpus, C. and Littleboy, A.K. (1998) An overview and update of the site characterization studies at Sellafield. Proceedings of the Yorkshire Geological Society, 52, 125-137.

Brace, W., Walsh, J. and Frangos, W. (1968) Permeability of granite under high pressure. Journal of Geophysical Research, 73, 2225-2236.

Brereton, N.R., Evans, C.J., Rogers, S.F., Kingdon, A. and Heaven, R.E. (1997) Geomechanical Modelling and Anisotropy at the Reservoir Scale. BGS Report No. WK/97/2C. British Geological Survey, Keyworth, Nottingham, UK.

Brudy, M., Zoback, M.D., Fuchs, K., Rummel, F. and Baumgärtner, J. (1997) Estimation of the complete stress tensor to $8 \mathrm{~km}$ depth in the KTB scientific drill holes: implications for crustal strength. Journal of Geophysical Research - Solid Earth, 102, 18,453-18,475.

Chadwick, R., Kirby, G. and Baily, H. (1994) The postTriassic structural evolution of north-west England and adjacent parts of the East Irish Sea. Proceedings of the Yorkshire Geological Society, 50, 91-102.

Cuss, R.J., Milodowski, A.E. and Harrington, J.F. (2011) Fracture transmissivity as a function of normal and shear stress: first results in Opalinus Clay. Physics and Chemistry of the Earth, Parts $A / B / C$, 36, 1960-1971.

Evans, C. and Brereton, N. (1990) In situ crustal stress in the United Kingdom from borehole breakouts. Geological Society, London, Special Publications, 48, 327-338.

Finkbeiner, T., Barton, C.A. and Zoback, M.D. (1997) Relationships among in-situ stress, fractures and faults, and fluid flow, Monterey Formation, Santa Maria Basin, California. AAPG Bulletin, 81, 1975-1999.

Gutierrez, M., Øino, L.E., and Nygård, R. (2000) Stressdependent permeability of a de-mineralised fracture in shale. Marine and Petroleum Geology, 17, 895-907.

Heffer, K. and Lean, J. (1993) Earth stress orientation a control on, and guide to, flooding directionality in a majority of reservoirs. Pp. 799-822 in: Reservoir Characterization III (W. Linville, editor). PennWell Books, Tulsa, Oklahoma, USA.

Huenges, E. and Will, G. (1989) Permeability, bulk modulus and complex resistivity in crystalline rocks. Pp. 361-375 in: Fluids Movements - Element Transport and the Composition of the Deep Crust (D. Bridgwater, editor). Kluwer Academic Publishers, Dordrecht, The Netherlands.

Jaeger, J.C., Cook, N.G.W. and Zimmerman, R.W. (2007) Fundamentals of Rock Mechanics. WileyBlackwell, Chichester, UK.

Laubach, S.E., Olson, J.E. and Gale, J.F.W. (2004) Are open fractures necessarily aligned with maximum horizontal stress? Earth and Planetary Science Letters, 222, 191-195. 


\section{STRESS HISTORY AND FLUID FLOW}

Lewis, C.L.E., Green, P.F., Carter, A. and Hurford, A.J. (1992) Elevated K/T palaeotemperatures throughout Nortwest England: three kilometres of Tertiary erosion? Earth and Planetary Science Letters, 112, $131-145$.

Michie, U. (1996) The geological framework of the Sellafield area and its relationship to hydrogeology. Quarterly Journal of Engineering Geology and Hydrogeology, 29, S13-S27.

Millward, D., Beddoe-Stephens, B., Williamson, I., Young, S. and Petterson, M. (1994) Lithostratigraphy of a concealed caldera-related ignimbrite sequence within the Borrowdale Volcanic Group of west Cumbria. Proceedings of the Yorkshire Geological Society, 50, 25-36.

Nirex (1996) Assessment of the In-situ Stress Field at Sellafield - Main Report. UK Nirex Ltd. Report No. SA/96/004.

Nirex (1997) Locations of Flow Zones in Sellafield Deep Boreholes. UK Nirex Ltd. Report No. SA/97/073.

Paillet, F.L. and Kim, K. (1987) Character and distribution of borehole breakouts and their relationship to in situ stresses in deep Columbia River basalts. Journal of Geophysical Research, 92, 6223-6234.

Pratt, H., Swolfs, H., Brace, W., Black, A. and Handin, J. (1977) Elastic and transport properties of an in situ jointed granite. International Journal of Rock Mechanics and Mining Science and Geomechanical Abstracts, 14, 35-45.

Reeves, H. (2002) The Effect of Stress and Fractures on Fluid Flow in Crystalline Rocks, Cumbria. Unpublished $\mathrm{PhD}$ thesis, University of Durham, Durham, UK, 239 pp.

Reeves, H., Cuss, R. and Evans, C. (2003) Critical stress analysis as a predictor of fluid flow; the answer or just another piece of the jigsaw? In: Proceedings
Fault and Top Seals: What do we know and where do we go? EAGE Conference, Montpellier, France, 8-11 September 2003.

Rice, J.R. (1992) Fault stress states, pore pressure distributions, and the weakness of the San Andreas Fault. International Geophysics, 51, 475-503.

Rider, M.H. (1986) The Geological Interpretation of Well Logs. Whittles, Caithness, UK.

Rogers, S.F. (2003) Critical stress-related permeability in fractured rocks. Pp. 7-16 in: Fracture and In-situ Stress Characterization of Hydrocarbon Reservoirs (M. Ameen, editor) Geological Society, London.

Rogers, S.F. and Evans, C.J. (2002) Stress-dependent flow in fractured Rocks at Sellafield, United Kingdom. Pp. 241-250 in: Geological Applications of Well Logs (M. Lovell and N. Parkinson, editors). AAPG Methods in Exploration No. 13. The American Association of Petroleum Geologists, Tulsa, Oklahoma, USA.

Rutqvist, J., Börgesson, L., Chijimatsu, M., Hernelind, J., Jing, L., Kobayashi, A. and Nguyen, S. (2009) Modeling of damage, permeability changes and pressure responses during excavation of the TSX tunnel in granitic rock at URL, Canada. Environmental Geology, 57, 1263-1274.

Standen, E. (1991) Tips for analyzing fractures on electrical wellbore images. World Oil, 212, 99-118.

Tsang, C.F., Bernier, F. and Davies, C. (2005) Geohydromechanical processes in the Excavation Damaged Zone in crystalline rock, rock salt, and indurated and plastic clays - in the context of radioactive waste disposal. International Journal of Rock Mechanics and Mining Sciences, 42, 109-125.

Zoback, M.D., Moos, D., Mastin, L. and Anderson, R.N. (1985) Well bore breakouts and in situ stress. Journal of Geophysical Research - Solid Earth, 90, 5523-5530. 
